\title{
FUNGUS INFECTIONS IN LEPROSY
}

E. Muir.

Epidermophyton infection forms one of the most troublesome complications of leprosy in the tropics. It is found particularly in patients with widespread skin lesions of the neural type. These may have become more or less residual, leaving large flat hypopigmented anidrotic areas.

A relationship between anidrotic skin and fungus growth is suggested by a recent article by Peck and others on "Sweat as a 
Fungicide ".* They found that thermal sweat may have fungistatic and fungicidal properties at a $\mathrm{pH}$ below 7 . Concentrated heat sweat is fungistatic, even when alkalinized. The fungicidal properties of sweat are due to its content of acetic, proprionic, caproic, caprylic, lactic and ascorbic acids. These substances must be present in the proper concentration to exert a fungistatic or fungicidal effect. There seems to be a relation between the localization of fungus infection and the distribution of sweat on the surface of the body. Areas which are exposed to the greatest concentration of sweat seem to have less tendency to fungus infection. Contrary to the usual opinion, there is comparatively little sweating between the toes, though moisture is retained and the skin is apt to become maserated. It may be on this account that epidermophyton so commonly begins between the toes. Topical application of ingredients of sweat, in proper concentrations, have proved valuable in the treatment of fungus infections.

It would seem likely, therefore, that the proneness of many neural type cases of leprosy in the tropics to epidermophytic disease may be due to the absence of sweat. The greater part of the trunk may be covered with tinea in a patient in whom the leprous infection has long since died out. The fungous growth is often mistaken for active leprous disease. Such cases are in marked contrast to those in whom hyperidrosis of the trunk compensates for anidrosis of the limbs; in these the trunk is remarkably free of fungus.

Widespread tinea infection in lepers, whether it cover the trunk or is confined to the limbs, is particularly difficult to treat by ordinary remedies, and Peck's paper suggests a new method of treatment that is perhaps worth trying. The sweat from other patients may be difficult to obtain in sufficient quantity, but some of the ingredients of sweat, such as acetic acid or lactic acid, might be applied in dilute form at frequent intervals. In South India, where hydnocarpus oil is stored in earthenware jars, I have been told that the old deposit of oil in the bottom of the jars is used for rubbing on the skin of lepers. As this substance is likely to be rancid oil, containing a large quantity of fatty acids, it is possible that its acidity renders it valuable in controlling the growth of fungus, while at the same time softening the hard epithelium.

A prescription that has been found very useful in treating discrete lesions of fungus (tinea versicolor, cruris, circinata, \&c.)

* Arch. of Derm. \& Syph., Vol. 39, No. I, Jan. r939, p. т26. The Role of Sweat as a Fungicicle, by S. M. Peck et al. 
is as follows:- pure carbolic acid 2 parts, ichthyol 2 parts, tincture of iodine 2 parts, glycerine $\dot{4}$ parts, rectified spirit 4 parts. Painting on of this mixture is followed in a few days by exfoliation, after which it may be repeated if necessary.

Tinea shares with scabies the responsibility for being one of the chief localising factors of leprosy infection. Frequently lesions begin round old fungus patches, the irritation either aiding the entrance of bacilli through the skin, or fixing the infection circulating through the body. 